\title{
Dynamics under Uncertainty: Modeling Simulation and Complexity
}

\author{
Dragan Pamučar ${ }^{1, *(\mathbb{D})}$, Dragan Marinković ${ }^{2} \mathbb{D}$ and Samarjit Kar ${ }^{3}$ \\ 1 Department of Logistics, Military Academy, University of Defense in Belgrade, 11000 Belgrade, Serbia \\ 2 Faculty of Mechanical Engineering and Transport Systems, Technische Universitaet Berlin, \\ 10623 Berlin, Germany; dragan.marinkovic@tu-berlin.de \\ 3 Department of Mathematics, National Institute of Technology, Durgapur 713209, India; \\ samarjit.kar@maths.nitdgp.ac.in \\ * Correspondence: dpamucar@gmail.com; Tel.: +38-111-360-3188
}

check for updates

Citation: Pamučar, D.; Marinković, D.; Kar, S. Dynamics under Uncertainty: Modeling Simulation and Complexity. Mathematics 2021, 9, 1416. https://doi.org/10.3390/ math9121416

Received: 11 June 2021

Accepted: 16 June 2021

Published: 18 June 2021

Publisher's Note: MDPI stays neutral with regard to jurisdictional claims in published maps and institutional affiliations.

Copyright: (C) 2021 by the authors. Licensee MDPI, Basel, Switzerland. This article is an open access article distributed under the terms and conditions of the Creative Commons Attribution (CC BY) license (https:// creativecommons.org/licenses/by/ $4.0 /)$.
This issue contains the successful invited submissions [1-11] to a Special Issue of Mathematics on the subject area of "Dynamics under Uncertainty: Modeling Simulation and Complexity".

The dynamics of systems have proven to be very powerful tools in understanding the behavior of different natural phenomena throughout the last two centuries. However, the attributes of natural systems are observed to deviate from their classical state due to the effects of different types of uncertainties. In actuality, randomness and impreciseness are the two major sources of uncertainties in natural systems. Randomness is modeled by different stochastic processes, and impreciseness could be modeled by fuzzy sets, rough sets, the Dempster-Shafer theory, etc.

Hence, the behavior of dynamical systems with uncertain variables, parameters, and functions has attracted academic attention in the recent past. Similarly, the study of the dynamics manifested in complex networks, or an interaction network of individuals, has become popular in the last few decades. The study of collective dynamics in complex interaction networks has been proven to be useful in understanding collective dynamic phenomena such as the emergence of cooperation between rational agents, synchronization of signals as seen in a flashlight or fireflies, rumor spreading, or conscious forming of a social network, etc. Different methods of statistical mechanics are also successfully applied to the study such complex systems and to understand the emergence of different collective behaviors. When randomness and imprecision coexist in a system, the system is called a hybrid uncertain system. In such a system, the overall uncertainty is an aggregation of both types of uncertainties. However, in the context of modeling the behavior of complex natural systems, it is extremely important to analyze the effect of the appropriate uncertainty to understand the predictability of different phenomena. An example of such uncertain dynamical systems could be sited in different levels of the universe, ranging from the interaction of quantum particles to the complex interaction of biochemical molecules, such as signaling in the brain, or even in complex social interactions, such as while forming opinions.

This Special Issue includes the most important forecasting techniques applied to the modeling simulation and complexity in dynamic systems, such as, fuzzy multi-criteria techniques, artificial intelligence, the Dempster-Shafer approach, and heuristics.

Response to our call had the following statistics, Figure 1. 


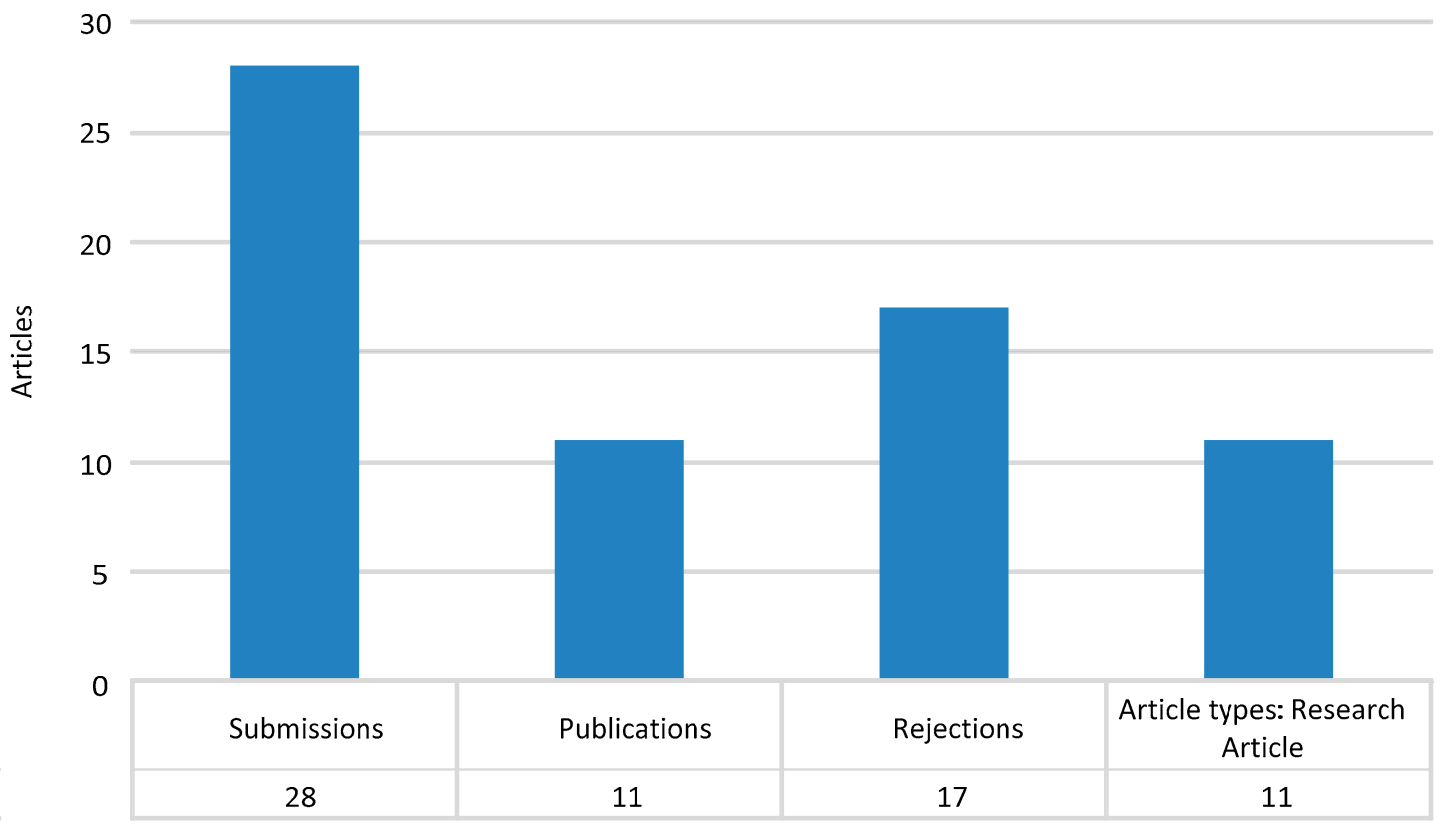

Figure 1. Special Issue statistics.

The geographical distribution of the authors (published papers) is presented in Table 1.

Table 1. Publications by country.

\begin{tabular}{cc}
\hline Countries & Countries \\
\hline Serbia & 7 \\
Bosnia and Herzegovina & 2 \\
China & 2 \\
South Africa & 2 \\
Turkey & 2 \\
Vietnam & 2 \\
Chile & 1 \\
India & 1 \\
Saudi Arabia & 1 \\
Spain & 1 \\
Iran & 1 \\
UK & 1 \\
\hline
\end{tabular}

Published submissions are related to road traffic risk analysis [1], dual-rotor systems [2], multi-criteria decision making [3,5,6,8,9], MIMO discrete-time systems [4], the classification and diagnosis of brain disease [7], data mining [10], and empathic building [11].

This Special Issue presents 11 models, which are briefly presented in the next section. Stanković et al. [1] proposed fuzzy Measurement Alternatives and Ranking according to the COmpromise Solution (fuzzy MARCOS) method for road traffic risk analysis. In addition, they used the fuzzy PIvot Pairwise RElative Criteria Importance Assessment-the fuzzy PIPRECIA method - to determine the weights of the criteria on the basis of which road network sections were evaluated. Fu et al. [2] investigated the non-probabilistic steadystate dynamics of a dual-rotor system with parametric uncertainties under two-frequency excitations. Žižović et al. [3] presented a new method for determining weight coefficients by forming a non-decreasing series at criteria significance levels (the NDSL method). Li et al. [4] investigated the problems of state feedback and the static output feedback preview controller for uncertain discrete-time multiple-input multiple-output systems based on the parameter-dependent Lyapunov function and the linear matrix inequality 
technique. Pribićević et al. [5] developed a new multi-criteria methodology that enables the objective processing of fuzzy linguistic information in the pairwise comparison of criteria, and they called it the fuzzy DEMATEL-D method. Žižović et al. [6] presented a new MADM method in their research called RAFSI (Ranking of Alternatives through Functional mapping of criterion sub-intervals into a Single Interval), which successfully eliminates the rank reversal problem. Hamzenejad et al. [7] introduced a new robust algorithm using three methods for the classification of brain disease: (1) the Wavelet-Generalized Autoregressive Conditional Heteroscedasticity-K-Nearest Neighbor method; (2) the Wavelet-GARCHKNN method; and (3) the Wavelet Local Linear Approximation. Pamučar et al. [8] presented an improved Best Worst Method for determining criteria weights in multi-criteria decision making. Ulutaş et al. [9] proposed a multiple-criteria decision-making approach for the selection of the optimal equipment for performing logistics activity. For defining the objective weights of the criteria, they applied the correlation coefficient and the standard deviation, and for the final ranking of the alternatives, they utilized the MARCOS method. Aleksić et al. [10] developed a prediction model that determines the most important factors for bleeding in liver cirrhosis. Salmeron and Ruiz-Celma [11] proposed an artificial intelligence-based approach to detect synthetic emotions based on Thayer's emotional model and Fuzzy Cognitive Maps.

We found the submissions and selections of papers for this issue very inspiring and rewarding. We also thank the editorial staff and reviewers for their efforts and help during the process.

Author Contributions: Conceptualization, D.P., D.M. and S.K.; methodology, D.P. and D.M.; formal analysis, S.K.; investigation, D.P.; supervision, D.M. and D.P. All authors have read and agreed to the published version of the manuscript.

Funding: This research received no external funding.

Conflicts of Interest: The authors declare no conflict of interest.

\section{References}

1. Stanković, M.; Stević, Ž.; Das, D.; Subotić, M.; Pamučar, D. A New Fuzzy MARCOS Method for Road Traffic Risk Analysis. Mathematics 2020, 8, 457. [CrossRef]

2. Fu, C.; Feng, G.; Ma, J.; Lu, K.; Yang, Y.; Gu, F. Predicting the Dynamic Response of Dual-Rotor System Subject to Interval Parametric Uncertainties Based on the Non-Intrusive Metamodel. Mathematics 2020, 8, 736. [CrossRef]

3. Žižović, M.; Pamučar, D.; Ćirović, G.; Žižović, M.; Miljković, B. A Model for Determining Weight Coefficients by Forming a Non-Decreasing Series at Criteria Significance Levels (NDSL). Mathematics 2020, 8, 745. [CrossRef]

4. Li, L.; Liao, F. Preview Control for MIMO Discrete-Time System with Parameter Uncertainty. Mathematics 2020, 8, 756. [CrossRef]

5. Pribićević, I.; Doljanica, S.; Momčilović, O.; Das, D.; Pamučar, D.; Stević, Ž. Novel Extension of DEMATEL Method by Trapezoidal Fuzzy Numbers and D Numbers for Management of Decision-Making Processes. Mathematics 2020, 8, 812. [CrossRef]

6. Žižović, M.; Pamučar, D.; Albijanić, M.; Chatterjee, P.; Pribićević, I. Eliminating Rank Reversal Problem Using a New MultiAttribute Model-The RAFSI Method. Mathematics 2020, 8, 1015. [CrossRef]

7. Hamzenejad, A.; Jafarzadeh Ghoushchi, S.; Baradaran, V.; Mardani, A. A Robust Algorithm for Classification and Diagnosis of Brain Disease Using Local Linear Approximation and Generalized Autoregressive Conditional Heteroscedasticity Model. Mathematics 2020, 8, 1268. [CrossRef]

8. Pamučar, D.; Ecer, F.; Cirovic, G.; Arlasheedi, M. Application of Improved Best Worst Method (BWM) in Real-World Problems. Mathematics 2020, 8, 1342. [CrossRef]

9. Ulutaş, A.; Karabasevic, D.; Popovic, G.; Stanujkic, D.; Nguyen, P.; Karaköy, Ç. Development of a Novel Integrated CCSD-ITARAMARCOS Decision-Making Approach for Stackers Selection in a Logistics System. Mathematics 2020, 8, 1672. [CrossRef]

10. Aleksić, A.; Nedeljković, S.; Jovanović, M.; Ranđelović, M.; Vuković, M.; Stojanović, V.; Radovanović, R.; Ranđelović, M.; Ranđelović, D. Prediction of Important Factors for Bleeding in Liver Cirrhosis Disease Using Ensemble Data Mining Approach. Mathematics 2020, 8, 1887. [CrossRef]

11. Salmeron, J.; Ruiz-Celma, A. Synthetic Emotions for Empathic Building. Mathematics 2021, 9, 701. [CrossRef] 